Théologiques

Théologiques

\title{
Chrétiens et Juifs : pour aller plus loin
}

\section{Menahem R. Macina}

Volume 11, numéro 1-2, automne 2003

Juifs et chrétiens. L’à-venir du dialogue.

URI : https://id.erudit.org/iderudit/009537ar

DOI : https://doi.org/10.7202/009537ar

Aller au sommaire du numéro

Éditeur(s)

Faculté de théologie de l'Université de Montréal

ISSN

1188-7109 (imprimé)

1492-1413 (numérique)

Découvrir la revue

Citer cet article

Macina, M. R. (2003). Chrétiens et Juifs : pour aller plus loin. Théologiques, 11(1-2), 285-320. https://doi.org/10.7202/009537ar

\section{Résumé de l'article}

Les sujets théologiques controversés qui divisent radicalement Juifs et chrétiens pourraient être abordés au cours de débats apparentés aux anciennes disputationes, mais menés dans un esprit de communion et d'estime mutuelle. À titre d'exemple, l'auteur explore quatre questions : (1) Comment concilier " le royaume vous sera enlevé » (Mt 21,43) avec l'irrévocabilité de l'alliance entre Dieu et le peuple juif, reconnue par l'Église ? (2) Le royaume messianique s'établira-t-il sur la terre, ou dans les cieux ? (3) Jésus peut-il être le Messie promis aux Juifs, alors que tant de prophéties ne sont pas accomplies et qu'Élie n'est pas venu (Ml 4,5) ? (4) L'État d'Israël : fait politique sans rapport avec l'histoire du salut ou " prémices de l'éclosion de la rédemption d’Israël " ? 


\title{
Chrétiens et Juifs : pour aller plus loin
}

\author{
Menahem R. Macina \\ Collaborateur scientifique \\ Université Libre de Bruxelles
}

L'approfondissement de la connaissance mutuelle entre chrétiens et Juifs se poursuit de manière régulière — on peut même dire spectaculaire surtout dans le monde anglo-saxon. En témoigne la littérature technique — spécialement théologique - extrêmement abondante, voire pléthorique, dont la maîtrise excède déjà nettement les capacités d'un chercheur isolé. Des institutions d'enseignement ont été créées, soit dans le cadre institutionnel de l'Église, soit à l'échelon universitaire (nombreuses chaires spécialisées) ${ }^{1}$. En témoigne également la multiplication des ouvrages et articles de chercheurs juifs et israéliens, consacrés au christianisme ${ }^{2}$.

1. Voir, entre autres, J. SiEvers, «Les multiples aspects des Études juives à Rome ", SIDIC (Service international de documentation judéo-chrétienne), 28/1 (1995) p. 17-21; J.-C. AtTias et P. Gisel, dir., Enseigner le judaïsme à l'Université, Genève, Labor et Fides, 1998.

2. Quelques titres, parmi d'autres, en français: J. KLAUSner, Jésus de Nazareth, sa vie, son temps, sa doctrine (Bibliothèque historique), Paris, Payot, 1933 (hébreu 1922); J. IsAac, Jésus et Israël, Paris, Grasset, 19592 (1946); S. Asch, Le Nazaréen, Paris, Nagel, 1947; G. Vermes, Jésus le Juif. Les documents évangéliques à l'épreuve d'un historien, Paris, Desclée de Brouwer, 1978; P. LAPIDE, Fils de Joseph? Jésus dans le judaïsme d'aujourd'hui et d'hier, Paris, Desclée de Brouwer, 1978; F. Rosenzweig, L'étoile de la Rédemption, Paris, Seuil, 1982; S. Ben-Chorin, Mon frère Jésus. Perspectives juives sur le Nazaréen, Paris, Seuil, 1983; idem, Paul. Un regard juif sur l'Apôtre des Gentils / trad. par P. Kessler, Paris, Desclée de Brouwer, 1999 (allemand 1970); B. Chouraqui, Jésus le Rabbi de Nazareth, Paris, La Différence, 1990; B. Finkelstein, L'écrivain juif et les Evangiles, Paris, Beauchesne, 1991; E. Fleg, Jésus raconté par le Juif errant, Paris, Albin Michel, $1993^{2}$ (1934); A.A. Кавак, Sur un sentier étroit. Pas à pas avec Jésus de Nazareth, Paris, Cerf, 
Le communiqué de presse qui suit (11 mars 2004) illustre, s'il en était besoin, même si c'est de manière ponctuelle, la vitalité et le sérieux de ce dialogue, à l'échelon institutionnel religieux.

Des cardinaux, évêques et prêtres français viennent de participer à plusieurs rencontres, à l'initiative du Congrès juif mondial (CJM), entre les courants orthodoxes du judaisme et la hiérarchie catholique. Une délégation de neuf évêques français, conduite par le cardinal Jean-Marie Lustiger, archevêque de Paris, est rentrée, samedi [6 mars], de New York, où elle a rencontré des représentants de l'orthodoxie juive pour des échanges sur le thème "tradition et modernité ». Cette visite de six jours intervient après une rencontre à New York de cardinaux $d u$ monde entier et de représentants du judaïsme orthodoxe, les 19 et 20 janvier [2004], sur le thème: «Quel est le premier des commandements?» [...] Ces rencontres d'une "grande richesse» témoignent de la volonté du judaïsme orthodoxe et ultra-orthodoxe, particulièrement vivant aux Etats-Unis, "d'entrer dans une nouvelle ère de dialogue avec l'Église catholique dépassant la sphère des spécialistes ", a déclaré le secrétaire du Comité épiscopal français pour les relations avec le judaïsme... ${ }^{3}$

On ne peut que souscrire au témoignage de ce responsable catholique français du dialogue avec le judaïsme. Mais, si utiles, voire indispensables, que soient de telles rencontres, elles n'ont jamais trait aux questions cruciales qui divisent encore chrétiens et Juifs, sans doute parce que la nature de ce dialogue lui interdit d'aborder des sujets controversés. Dans ce cas, il faudrait envisager un autre cadre pour en traiter. On pourrait, par exemple, renouer avec l'ancienne tradition des disputationes, en la modernisant et en la menant dans un esprit de communion et d'estime

19962 (1937); J. Grunewald, Chalom Jésus! Lettre d'un rabbin d'aujourd'hui au rabbi de Nazareth, Paris, Albin Michel, 2000; A. AbéCAssis, "En vérité je Vous Le dis ». Une lecture juive des Évangiles, Paris, Éditions n 1, 1999; S. Malka, Jésus rendu aux siens. Enquête en Israël sur une énigme de vingt siècles, Paris, Albin Michel, 1999; Jésus raconté par les juifs. Textes du II au Xe siècle [sic] / trad. de l'hébreu et de l'araméen par J.-P. Osier, Paris, Berg International, 1999; G. IsraëL, La question chrétienne. Une pensée juive du christianisme, Paris, Payot, 1999; L. BAEck, Les Évangiles, une source juive / trad. par M.-R. Hayoun, Paris, Bayard, 2002 (allemand 1938); D. Flusser, Les sources juives du christianisme. Une introduction / trad. par E. Lasry, Paris/Tel Aviv, L'Éclat, 2003 (hébreu 1980).

3. Résumé détaillé d'après les notes prises par C. Maison lors du Symposium, dans "Des Cardinaux et des Rabbins se rencontrent à New York ", Sens, 8 (2004) p. 453-473. 
mutuelle. Rappelons que la disputatio était l'une des principales méthodes d'enseignement et de recherche dans les universités médiévales. Il s'agissait d'une discussion organisée de questions issues de la lecture des textes ou de questions indépendantes. Laissant de côté l'aspect joute oratoire de ces disputations publiques, où un maître de l'université exposait et défendait une thèse contre des objections, et les règles formelles de l'Ars obligatoria ayant pour but d'empêcher la discussion de glisser, on en reviendrait à l'esprit originel du débat ${ }^{4}$, dont la fécondité est grande, pourvu qu'il se déroule dans une atmosphère de respect mutuel, et que celles et ceux qui y participent viennent autant pour apprendre ce qu'ils ignorent, que pour exposer ce qu'ils savent.

À mi-chemin entre les symposiums scientifiques et les rencontres dialogiques, des débats sur des questions disputées pourraient constituer des lieux d'échanges intellectuels et spirituels plus spontanés, d'où seraient exclues toutes tentatives, directes ou indirectes, d'intimider, voire de convaincre d'erreur les participants dont on ne partage ni la foi ni les idées. Les Juifs y pratiqueraient le pacifique masa umatan (litt. "négociation ») talmudique 5 . Quant aux chrétiens, il leur serait loisible de recourir à leurs modes favoris d'argumentation religieuse et exégétique: la typologie et le sens spirituel ${ }^{6}$.

4. Voir l'excellent exposé de vulgarisation, intitulé «Le débat», en ligne sur le site canadien: <www.cafe.umontreal.ca/genres/n-debat.html>.

5. Ayant fait l'expérience de l'inutilité des tentatives de résister de front à la puissance des empires, au plan politique, et à celle de la chrétienté, au plan religieux, les Sages juifs ont très vite opté pour la cohabitation avec les nations du monde be-darkhei shalom ("par les voies de la paix»). Leurs méthodes étaient l'éducation, la discussion, le compromis et la recherche du consensus. Le Talmud ne se comprend que par le masa umatan ( l'échange et la négociation»), qui permet de trouver la meilleure manière d'exprimer son désaccord par les voies de la logique et de la persuasion. Cette approche rabbinique du désaccord et des divergences d'opinion constitue un modèle positif pour la résolution des conflits d'interprétation, voire des antagonismes, entre personnes, et est appréciée et utilisée, aujourd'hui encore, pour faire face à des divergences irréconciliables.

6. Voir la section II : «Rapports entre Ancien et Nouveau Testament [sic]» dans le document de la Commission du SAint-Siège pour les relations avec le JUdAÏsme, Notes pour une correcte présentation des juifs et du judaïsme dans la prédication et la catéchèse de l'Église catholique (24 juin 1985), publié dans Istina, 31 (1986) p. 207-219. 
Et pour éviter que, lors de ces débats, ne soient traités que des thèmes consensuels, ou extrinsèques au contenu de foi de l'une et l'autre confessions, juive et chrétienne, il serait souhaitable que soient abordés, avec courage et sans complexe - de supériorité ou d'infériorité - des sujets qui divisent, parfois radicalement, Juifs et chrétiens, et qui, pour des raisons diverses, n'ont jamais fait l'objet d'un dialogue spécifique et exigeant. On proposera, ici, quelques thèmes qui touchent au tréfonds même des contenus de foi et de la conception du monde, juifs et chrétiens, et qu'il est d'autant moins question d'éviter qu'ils s'enracinent dans les mêmes Écritures, lesquelles sont interprétées de manière différente et parfois radicalement divergente par les fidèles de l'une et l'autre confessions de foi. Les implications doctrinales des questions que soulèvent les sujets proposés sont d'autant plus importantes et sensibles, que trois d'entre eux concernent la fin des temps et l'avènement du royaume messianique, doctrines peu enseignées aux fidèles chrétiens par les Églises officielles, et traitées par leurs théologiens presque uniquement comme des questions académiques relevant des sciences bibliques ${ }^{7}$.

À titre indicatif, et sans que cette liste doive être considérée comme limitative, voici donc quatre questions cruciales qui pourraient faire l'ob-

7. Exemple type: R. Schnackenburg, Règne de Dieu et Royaume de Dieu. Essai de théologie biblique, Paris, L'Orante, 1965. Vues plus novatrices chez B.T. Viviano, Le Royaume de Dieu dans l'histoire, Paris, Cerf, 1992. Peu de théologiens sont allés aussi loin dans l'approfondissement théologique et l'actualisation de ces notions que J. Moltmann, La venue de Dieu. Eschatologie chrétienne (Cogitatio Fidei 220), Paris, Cerf, 2000, qui consacre entièrement le long ch. 3 de son ouvrage au Royaume, sous le titre «Règne de Dieu. Eschatologie historique », p. 165-311; mais ses vues sont loin d'être reçues dans les milieux théologiques, certains les considérant même comme "aventureuses", sans doute parce que leur audace les dérange. En règle générale, on constate une nette frilosité, dans la théologie chrétienne, à l'égard de l'eschatologie, qui est souvent considérée comme une tendance à s'évader de la réalité du monde. Un échantillon particulièrement représentatif de cette perception, d'autant plus pénible qu'elle émane d'un exégète, aujourd'hui disparu, qui a beaucoup contribué à une meilleure compréhension de textes du Nouveau Testament à la lumière de leur substrat hébreu, est l'ouvrage de J. CARMignAC, Le mirage de l'eschatologie, Paris, Letouzey et Ané, 1978. Heureusement, les choses commencent à évoluer. Outre les vues novatrices de Moltmann, on lira, par exemple, avec profit: P. de LAubier, Le temps de la fin des Temps. Essai sur l'eschatologie chrétienne, Paris, François-Xavier de Guibert, 1994 ; idem, L'eschatologie (Que sais-je? 3352), Paris, Presses Universitaires de France, 1998. 
jet des débats envisagés. (1) Comment concilier «le royaume vous sera enlevé » avec l'irrévocabilité de l'alliance divine avec le peuple juif, reconnue par l'Église? (2) Le royaume messianique s'établira-t-il sur la terre, ou dans les cieux? (3) Jésus peut-il être le Messie promis aux Juifs, alors que tant de prophéties ne sont pas accomplies et qu'Élie n'est pas venu? (4) L'État d'Israël: fait politique sans rapport avec l'histoire du salut ou «prémices de l'éclosion de la rédemption d'Israël» ?

\section{Si «le royaume a été enlevé» au peuple juif, l'alliance divine avec lui n'est pas «irrévocable» comme l'affirme l'Église}

Les chapitres 21 à 23 de l'Évangile de Matthieu relatent les violentes controverses entre Jésus et les scribes et les pharisiens. L'opposition se fait de plus en plus vive au fil des versets. Elle culmine dans la parabole des vignerons homicides (Mt 21,33-42) et dans la phrase qui la clôt: "Aussi, je vous le dis: le Royaume de Dieu vous sera retiré et sera donné à un peuple qui en porte les fruits ${ }^{8}$.» (v. 43) Comment les artisans chrétiens du dialogue avec le peuple juif peuvent-ils concilier cette dépossession, donnée comme annoncée par Jésus lui-même, avec deux autres passages du Nouveau Testament, qui semblent la contredire radicalement?

Ainsi, le premier chapitre du livre des Actes des Apôtres nous relate la question cruciale que les disciples posent à Jésus (présenté comme ressuscité): "Étant donc réunis, ils l'interrogeaient ainsi : "Seigneur, estce maintenant le temps où tu vas rendre le royaume à Israël ?” » (v. 6) On admettra qu'il n'est pas concevable que la malédiction attribuée à Jésus en Mt 21,43 se soit si vite effacée de leur mémoire. Or, dans ce récit du premier chapitre des Actes, il n'est fait état d'aucune allusion de Jésus à la dépossession du royaume, fulminée par lui antérieurement. Au contraire, il répond positivement à l'interrogation, même si c'est pour reporter à plus tard la solution de cette aporie apparente: "Il ne vous appartient pas de connaître les temps et moments que le Père a fixés de sa seule autorité. » (Ac 1,7)

Autre contradiction apparente: l'affirmation suivante de l'apôtre Paul: «Dieu n'a pas rejeté le peuple qu'il a discerné par avance.» (Rm 11,2) Le pape Jean-Paul II en a respecté l'esprit, lorsqu'il a parlé, dans un discours à l'adresse de la communauté juive allemande (Mayence,

8. Ici comme ailleurs dans cet article, c'est moi qui souligne. 
1980), du «peuple de Dieu de l'ancienne Alliance - une Alliance qui n'a jamais été révoquée par Dieu ${ }^{9}$ ». Faisant ainsi implicitement allusion à cet autre verset de l'épître aux Romains: "Car les dons et l'appel de Dieu sont irrévocables. » $(11,29)$

Quant à la Tradition juive, bien que consciente des péchés du peuple, non seulement elle se fie aux promesses bibliques — telle celle-ci: "Quand vos péchés seraient comme l'écarlate, comme neige ils blanchiront; quand ils seraient rouges comme la pourpre, comme laine ils deviendront» (Es 1,18) —, mais encore, elle énonce par la bouche des Sages de la Mishna: "Tout Israël a part au monde à venir " (Talmud de Babylone Sanhedrin 90a). Mais le plus étonnant est le texte suivant de Maïmonide (XII ${ }^{\mathrm{e}} \mathrm{s}$ ), qui semble calqué sur le verset 6 du premier chapitre des Actes des Apôtres, cité ci-dessus: "En vérité les "jours du Messie" sont l'époque où sera rétablie la souveraineté d'Israël... ${ }^{10}$ »

\section{Le royaume messianique s'établira-t-il sur la terre, ou dans les cieux?}

Malgré les apparences, il ne s'agit pas ici de pure spéculation. La Tradition juive tient que la royauté divine s'exercera sur la terre sous l'égide d'un Messie humain ${ }^{11}$. Elle s'appuie sur les Écritures et trouve une de ses

9. Texte original allemand dans L'Osservatore Romano (17-18 novembre 1980), reproduit dans Acta Apostolicae Sedis, 73 (1981) p. 80. Il a fait l'objet d'une traduction française, malheureusement défectueuse, dans Documentation Catholique, $\mathrm{n}^{\circ} 1798$ (21 décembre 1980) p. 1148-1149, et d'une traduction corrigée dans Istina 31 (1986) p. 192-195 (ici p. 193-194).

10. «Introduction au chapitre Heleq", dans M. MAÏmonide, Épîtres («Les Dix Paroles ») / trad. de l'hébreu par J. de Hulster, Paris, Verdier, 1983, p. 159-195 (ici p. 177). Ci-après: «Heleq".

11. Sur cette question difficile, il faut savoir que la tendance majeure du judaïsme traditionnel en matière de messianisme est extrêmement prudente. Les expériences traumatisantes de ce qu'ont coûté au peuple juif les prétendus messies - de Jésus à Sabbataï Tsevi, en passant par Bar Kochba - ont fait de ce thème, sinon un sujet tabou, du moins une question à propos de laquelle la plus grande réserve s'impose. MAİMONIDE fut le représentant majeur de cette tendance sévère - voir en particulier son "Épître au Yemen ", dans MAïmonide, Épîtres, p. 45-114. Un penseur juif moderne, Y. Leibowitz, s'inscrit dans la ligne du grand philosophe juif médiéval (voir J.-M. Joubert, Foi juive et croyance chrétienne, Paris, Desclée de Brouwer, 2001, ch. 7: «Histoire et messianisme», p. 165-199). Sur ce sujet, on se limitera ici à quelques repères bibliographiques: G.G. ScHolem, Le messianisme juif. Essai sur la spiritualité du judaïsme / préface, trad., notes et bibliographie par B. Dupuy, 
expressions les plus nettes dans le célèbre aphorisme talmudique: "la seule différence entre le monde présent et le temps du Messie c'est qu'aura cessé l'asservissement d'Israël aux nations " (Talmud de Babylone Sanhedrin 91b et Berakhot 34b). Une grande partie des aphorismes des Sages d'Israël ayant trait aux temps messianiques sont rassemblés dans le chapitre 11 et dernier du Talmud Sanhedrin, intitulé "Heleq", parce qu'il commence par la mishna, déjà citée, "Kol Yisra'el iesh lahem beleq be'olam haba"» ("Tout Israélite [ou tout Israël] a part au monde à venir ${ }^{12}$ »). Maïmonide a composé une "Introduction au chapitre Heleq ", dont le but est de donner une explication rationnelle des passages aggadiques du Talmud, qui lui paraissaient beaucoup trop fabuleux. Malgré cette réduction philosophique, la lecture de cet opuscule est utile en ce qu'il expose l'essentiel des doctrines eschatologiques juives. On peut y lire, par exemple et entre autres : "Ils reviendront en terre d'Israël; et ce roi [Messie] sera très grand; le siège de son royaume à Sion fera grandir son nom et sa réputation atteindra toutes les nations... ${ }^{13}$ » Et surtout le douzième des Treize Principes formulés par le grand philosophe et théologien juif médiéval:

Les jours du Messie: croire et être sûr qu'il viendra et ne pas penser qu'il sera en retard. "Si elle [la venue du Messie] diffère, attends-le [le Messie] » [voir Ha 2,3]. Ne lui assigne pas une date et ne cherche pas dans les Écritures pour déduire le moment de sa venue [...]. Et celui qui éprouve des doutes [sur sa venue] ou qui minimise sa dignité - renie la Tora qui l'a annoncé explicitement dans la péricope de Balaam [Nb 23-24], et dans celle de Nitsavim [Dt 30, 3-5] [...] il ne peut y avoir de roi en Israël en dehors de la maison de David et de la postérité de Salomon [voir 2 S 7,13].

Paris, Calmann-Lévy, 1974 (anglais 1971); B. Gross, Messianisme et histoire juive, Paris, Berg International, $1997^{2}$ (1977); J.-C. AtTiAs, Isaac Abrabanel, la mémoire et l'espérance, Paris, Cerf, 1992; D. Banon, Le Messianisme (Que sais-je? 3377), Paris, Presses Universitaires de France, 1998; J.-C. Attias, P. Gisel et L. Kaenel, dir., Messianismes. Variations sur une figure juive, Genève, Labor et Fides, 2000 (ouvrage recommandé, tant pour les contributions compétentes qu'il contient que pour son excellente bibliographie); etc.

12. Texte français cité d'après La Guemara, le Talmud de Babylone / trad. par les membres du Rabbinat français, Sanhedrin / trad. par I. Salzer, Paris, Keren Hasefer ve Halimoud, CLKH, 1974, p. 442-571.

13. «Heleq", p. 177. 
Et quiconque diffère d'opinion à propos de cette famille renie Dieu, béni soit-il, et les paroles de ses prophètes ${ }^{14}$.

Il en va différemment dans la doctrine chrétienne, qui enseigne, depuis de longs siècles, qu'avant d'advenir en gloire dans les cieux, après la fin du monde, la royauté de Dieu s'exerce mystérieusement, au fil des siècles, dans l'âme des fidèles, conformément à ces versets de l'Évangile: «Les Pharisiens lui ayant demandé quand viendrait le Royaume de Dieu, il leur répondit: "La venue du Royaume de Dieu ne se laisse pas observer, et l'on ne dira pas: Voici : il est ici! Ou bien : il est là ! Car voici que le Royaume de Dieu est au milieu [ou au-dedans] de vous". " (Lc 17,20-21)

Pourtant la prière que Jésus enseigna à ses disciples - et qui est passée à la postérité chrétienne sous le nom de «Notre Père » — comporte une demande qui semble accréditer le caractère terrestre du Règne de Dieu, à la fin des temps: "Que ton règne advienne... sur la terre comme au ciel »(Mt 6,10). Un commentaire latin de cette prière, dû à l'évêque Cyprien de Carthage (III ${ }^{\mathrm{e}}$ s.) le comprend ainsi:

Nous demandons que le règne de Dieu s'actualise en nous, dans le même sens où nous implorons qu'en nous son nom soit sanctifié. [...] Nous demandons que vienne notre règne - celui que Dieu nous a promis et que le Christ nous a acquis par son sang et sa passion - afin qu'après avoir été serviteurs dans ce siècle, nous régnions avec le Christ dominateur. Luimême nous en donne l'assurance, quand il dit: "Venez, les bénis de mon Père. Recevez le royaume préparé pour vous dès le commencement du monde $^{15}$.» (cf. Mt 25,34)

Mais cette interprétation a contre elle l'opinion de nombreux biblistes qui estiment qu'à s'en tenir au texte grec de l'Évangile de Mat-

14. «Heleq", p. 193-194.

15. Saint Cyprien, L'Oraison dominicale (Études d'histoire et de philosophie religieuses 58) / texte, trad. et notes par M. Réveillaud, Paris, Presses Universitaires de France, 1964, p. 94-97. On notera qu'à en croire le même Évangile, dans ce Royaume, on mange et on boit, comme l'atteste ce passage: «... beaucoup viendront du levant et du couchant prendre place au festin avec Abraham, Isaac et Jacob dans le Royaume des Cieux..." (Mt 8,11), que, bien entendu, à l'exception des Pères dits «millénaristes» — dont Irénée de Lyon (voir note 20, ci-après) —, la Tradition chrétienne presque unanime a interprété de manière spirituelle comme décrivant "le règne des élus dans les cieux ». 
thieu, les mots «sur la terre comme au ciel» se rapportent exclusivement à la demande qui précède: "que ta volonté soit faite». L'un d'entre eux, toutefois, a voulu aller plus loin et a réalisé une enquête approfondie sur ce point précis ${ }^{16}$. Il évoque, entre autres, un passage du Catéchisme $d u$ Concile de Trente (1566):

Mais pour mieux faire comprendre la force et la valeur de cette demande, le Pasteur aura grand soin de montrer aux Fidèles que ces mots: sur la terre comme au ciel peuvent s'appliquer et s'étendre à chacune des trois premières parties de l'Oraison Dominicale, et signifier: que votre Nom soit sanctifié sur la terre comme au ciel; que votre Royanme arrive sur la terre comme au ciel; que votre Volonté soit faite sur la terre comme au ciel ${ }^{17}$.

Et Carmignac de proposer « une autre solution [qui] serait plus conforme au génie de la langue française: si l'on veut montrer clairement qu'un complément affecte plusieurs verbes, on le place normalement avant ces verbes. Ainsi l'on obtiendrait une traduction limpide:

Notre Père du Ciel!

Que, sur terre comme au Ciel,

Votre Nom soit glorifié,

Votre Règne arrive, Votre Volonté soit faite ${ }^{18}$ !

À quoi il convient d'ajouter qu'une solide tradition chrétienne, apostolique et patristique, tient que le royaume de Dieu s'instaurera sur la terre et durera au moins 1000 ans. Elle se fonde principalement sur l'Apocalypse de Jean (20,2-7), et on peut en lire plusieurs témoignages, difficilement réfutables, chez des auteurs aussi vénérables que Justin et Irénée de Lyon. Pour ces auteurs et pour d'autres ultérieurs, la «première résurrection " (voir Ap 20,5-6) aura lieu sur terre, et ces ressuscités régneront avec le Christ sur la terre.

16. J. Carmignac, Recherches sur le "Notre Père», Paris, Letouzey et Ané, 1969, ch. 9: "Sur terre comme au ciel», p. 110-117.

17. Cité ici d'après Catéchisme $d u$ Concile de Trente. Le Symbole des apôtres, les sacrements, le Décalogue, la prière / trad. par E. Marbeau et A. Carpentier, Bouère, D.M. Morin, 1998 (latin 1969), ch. 40: "Que votre nom soit sanctifié », $\mathbb{S}$ II: "Qu'est-ce que la gloire de Dieu? ", p. 495. Réimpression d'un numéro spécial de la revue Itinéraires paru en octobre 1969. Un préambule du directeur de la revue, J. Madiran, précisait qu'il reproduisait, avec l'autorisation des éditions Desclée et Cie, la traduction française Marbeau-Charpentier publiée avec un imprimatur donné à Tournai, le 17 juillet 1923.

18. Carmignac, Recherches sur le "Notre Père», p. 116. 
Justin ( $\mathrm{II}^{\mathrm{e}} \mathrm{s}$.) écrit :

[Le juif Tryphon apostrophe Justin:] Mais, dis-moi, professez-vous réellement que cet emplacement de Jérusalem sera rebâti ? que votre peuple s'y réunira avec le Messie et en même temps avec les patriarches, les prophètes, les saints de notre race...

[Réponse de Justin:] ... Je t'ai déclaré que moi-même et beaucoup d'autres avons ces idées, au point que nous savons parfaitement que cela arrivera; beaucoup, par contre, même chrétiens de doctrine pure et pieuse, ne le reconnaissent pas, je te l'ai signalé [...]. Pour moi et les chrétiens d'orthodoxie intégrale, tant qu'ils sont, nous savons qu'une résurrection de la chair arrivera pendant mille ans dans Jérusalem rebâtie, décorée et agrandie, comme les prophètes Ezéchiel, Isaïe et les autres l'affirment ${ }^{19}$.

Irénée de Lyon ( $\mathrm{III}^{\mathrm{e}} \mathrm{s}$.) déclare:

Ainsi donc, certains se laissent induire en erreur par les discours hérétiques au point de méconnaître les "économies» de Dieu et le mystère de la résurrection des justes et du royaume qui sera le prélude de l'incorruptibilité [...]. Aussi est-il nécessaire de déclarer à ce sujet que les justes doivent d'abord, dans ce monde rénové, après être ressuscités à la suite de l'Apparition du Seigneur, recevoir l'héritage promis par Dieu aux pères et y régner; ensuite seulement aura lieu le jugement de tous les hommes. Il est juste, en effet, que, dans ce monde même où ils ont peiné et où ils ont été éprouvés de toutes les manières par la patience, ils recueillent le fruit de cette patience; que, dans le monde où ils ont été mis à mort à cause de leur amour pour Dieu, ils retrouvent la vie; que, dans le monde où ils ont enduré la servitude, ils règnent [...]. Il convient donc que le monde luimême, restauré en son état premier, soit, sans plus aucun obstacle, au service des justes ${ }^{20}$.

Ces conceptions de Justin, d'Irénée de Lyon, et d'autres Pères de l’Église et écrivains ecclésiastiques n'ont pas bénéficié, dans l'Église, de la réception qu'elles méritent. Des théologiens contemporains n'ont pas hésité à les taxer de millénarisme (au sens hérétique du terme $)^{21}$. Il faut

19. «Dialogue avec Tryphon ", $\mathbb{S} 80$, dans Justin Martyr. Oeuvres complètes (Bibliothèque) / trad. de G. Archambault et L. Pautigny, revues et mises à jour par E. Gauché, Paris, Migne, 1994, p. 228-229.

20. Irénée de Lyon, Contre les Hérésies. Livre V (Sources Chrétiennes 153) / éd. critique par A. Rousseau, L. Doutreleau, s.j. et C. Mercier, Paris, Cerf, 1969, p. 397-399.

21. J'ai consacré trois études à cette difficile et délicate question: M. MACinA, «Le rôle 
souhaiter que cette doctrine patristique vénérable soit réhabilitée, car ses conceptions sont très consonantes avec celles de la Tradition juive concernant les yemot ha-mashiaḅ ( "temps du Messie»)22 et les ḩevlë̈ ha-mashiab ( «douleurs de l'enfantement du Messie») qui, aux dires des prophètes, précéderont l'ère messianique, thème que l'on trouve également dans le Nouveau Testament: "On se dressera, en effet, nation contre nation et royaume contre royaume. Il y aura par endroits des tremblements de terre, il y aura des famines. Ce sera le commencement des douleurs de l'enfantement.» (Mc 13,8)

\section{Jésus peut-il être le Messie promis aux Juifs, alors que tant de prophéties ne sont pas accomplies et qu'Élie n'est pas venu?}

\subsection{Apocatastase et "christologie du non-accomplissement"}

La question de l'accomplissement et/ou du non-accomplissement des prophéties est cruciale. Ce thème ne ressortit pas davantage que le précédent à la pure spéculation ni à quelque tendance mystique débridée. Pourtant, du fait de la carence de la réflexion théologique à ce propos, c'est à un auteur à l'approche mystique (mais non "débridée "), qu'il est fait appel ici pour exposer, au moins dans ses grandes lignes, cette problématique. Mahèqra est, à notre connaissance, le seul auteur à avoir traité, de manière novatrice - quoique très audacieuse et assez dérangeante de ce que certains appellent, à tort, me semble-t-il, l' «eschatologie déjà réalisée ». Il a élaboré une théorie originale pour tenter de rendre compte de l'étrangeté apparente de la croyance chrétienne en un Christ qui

des presbytres dans la transmission de la Tradition, chez Irénée de Lyon », dans Acta Orientalia Belgica, 13 (2000) p. 63-94; idem, "Le Royaume de Dieu sur la terre: une attente messianique commune aux Juifs et aux Chrétiens ", accessible en ligne sur <www.chretiens-et-juifs.org/article.php ?voir[]=45\&voir[]=4211>; idem, « La croyance en un Règne du Messie sur la terre: patrimoine commun aux Juifs et aux Chrétiens ou hérésie millénariste?", Cedrus Libani [revue catholique maronite libanaise éditée en France par Cariscript], 64 (2001) p. 39-51. Une mise à jour de ce dernier article (réintitulé «Le Royaume de Dieu sur la terre, attentes juives et chrétiennes») est disponible en ligne sur: <www.rivtsion.net/documents/showthread. php ?s=\&threadid $=2651>$.

22. Exemples dans MAhÈQRA, «Le témoignage des Sages d'Israël sur les temps messianiques", dans Le Royaume qui vient. Réflexions et méditations sur la Fin des Temps et l'avènement du Royaume messianique, ch. 11, en ligne sur <www.rivtsion. net/documents/showthread.php ?s=\&threadid=2607>. 
échoue, alors qu'il s'est proclamé lui-même Messie, et dont l'Église affirme, dans son Credo, qu' «il est ressuscité d'entre les morts", qu'il «viendra juger les vivants et les morts» et que «son règne n'aura pas de fin $^{23} »$. Selon cet auteur, pour résoudre toutes les apories qui découlent de l'interprétation traditionnelle du Nouveau Testament, il faut recourir à une notion, dont l'extraordinaire fécondité pour la compréhension de l'histoire du salut est passée totalement inaperçue depuis des siècles, et qui est totalement absente de la théologie actuelle: l'apokatastasis ( « apocatastase »).

Il serait trop long d'exposer ici le sens de cette notion et ses implications en matière d'eschatologie, tant chrétienne que juive. Disons simplement que le terme - qui figure une seule fois (hapax) dans le Nouveau Testament (Ac 3,21) — ne connote pas uniquement le «rétablissement ", comme le comprennent la quasi-totalité des traducteurs du Nouveau Testament, que critique Mahèqra, en ces termes:

Cette traduction déficiente escamote involontairement la portée prophétique et eschatologique de ce passage capital des Actes des Apôtres. La notion grecque d'apocatastase, n'a pas ici la connotation, chère aux anciens Grecs, d'une «restauration de la création dans son état primordial », après une catastrophe ultime, selon la conception d'un retour des astres à leur point de départ (restauration cyclique), ainsi que pourrait le laisser croire la traduction courante (Bible de Jérusalem): "jusqu'au temps de la restauration universelle dont Dieu a parlé par la bouche de ses saints prophètes». Elle n'a rien à voir non plus avec la doctrine origénienne condamnée par l'Église - d'un salut de tous, y compris des damnés. Le terme "apocatastase", dans ce verset, a le sens de règlement définitif et plénier de la situation d'incapacité où se trouvait son peuple de bénéficier

23. Cette formule apparaît pour la première fois dans la «Profession de foi » du 1er Concile de Constantinople ( $2^{\mathrm{e}}$ Concile œcuménique), qui se tint en mai-juillet 381 ; H. Denzinger, Symboles et définitions de la foi catholique / trad. par les Éditions du Cerf, Paris, Cerf, 1996 (allemand 199177), p. 150. Cette formulation est encore aujourd'hui celle de la forme longue du Credo récité au cours de la messe, dans le culte catholique. On remarquera que ce paragraphe du Credo est une reprise littérale d'un passage de l'Évangile de Luc, relatant l'épisode de «l'Annonce " faite à Marie, attribuée à l'ange Gabriel (Lc 1,33), sous la forme: "tès basileias autou ouk estai telos ", que l'on retrouve dans ce stique du Credo du Concile de Constantinople, sous la forme: "ou tès basileias ouk estai telos". Bel exemple de citation implicite, fréquent dans les textes religieux anciens, tant juifs que chrétiens, notamment dans la liturgie. 
de l'accomplissement plénier des promesses divines. Et plutôt que de traduire mot à mot le terme apokatastasis, aux connotations aussi riches que peu familières à nos mentalités, avec pour résultat d'en obscurcir le sens, on en proposera la paraphrase suivante: "jusqu'aux temps de la restauration définitive de tout ce dont Dieu a parlé par la bouche de ses saints prophètes d'autrefois ${ }^{24}$.»

D'un point de vue chrétien, grâce à ce concept d' "apocatastase ", il semblerait donc qu'il y ait place pour une christologie qui assume une part de non-accomplissement. Et s'agissant du non-accomplissement de toutes les prophéties, Mahèqra ajoute:

8. [...] Toutefois, l'accomplissement des Écritures et la prédication du Royaume des cieux, qui en est le corollaire, constituent à la fois le point commun et la pomme de discorde entre le Judaïsme et l'Église, voire entre les chrétiens eux-mêmes. Pour ces derniers, le Christ est l'aboutissement des Écritures. Ils se basent sur des passages comme celui-ci: Si vous croyiez Moïse, vous me croiriez aussi, car il a écrit de moi (Jean 5, 46).

9. Mais Moïse n'a pas écrit que du Christ. Maints autres textes, sans contredire le christocentrisme de l'Écriture, en étendent, au contraire, la perspective. À preuve: Et, commençant par Moïse et parcourant tous les Prophètes, [Jésus] leur interpréta, dans toutes les Écritures, ce qui le concernait. Et encore: Puis il leur dit: Telles sont bien les paroles que je vous ai dites, quand j'étais encore avec vous: il faut que s'accomplisse tout $c e$ qui est écrit de moi dans la Loi de Moïse, les Prophètes et les Psaumes. Et enfin: Car, je vous le dis, il faut que s'accomplisse en moi ceci qui est écrit: Il a été compté parmi les scélérats. Aussi bien, ce qui me concerne touche à sa fin. (Lc 24, 27.44; Lc 22, 37).

10. Il y a donc, dans les Écritures, ce qui concerne le Christ seul, et dont l'essentiel est déjà accompli, et ce qui concerne le Peuple de Dieu, les nations, le devenir des individus et de la création tout entière, et qui reste à accomplir. Jésus Lui-même en témoigne, lorsqu'il dit: Ne croyez pas que

24. MAHÈQRA, «Une œuvre que vous ne croiriez pas si on venait vous la raconter », dans Le Royaume qui vient, ch. 4, en ligne sur <www.rivtsion.net/documents/showthread. php $? \mathrm{~s}=\&$ threadid $=2490>$. Les traductions des passages du Nouveau Testament qui figurent dans ce paragraphe sont miennes; elles ont été faites à partir de l'original grec et diffèrent notablement des versions habituelles (d'où les italiques), en raison de ma saisie particulière du sens du verbe apokathistanai et du substantif apokatastasis, habituellement compris comme signifiant "rétablir», "rétablissement", et autres variantes et synonymes de cette acception. 
je sois venu abolir la Loi ou les Prophètes. Je ne suis pas venu abolir mais accomplir. Car je vous le dis, en vérité : avant que ne passent le ciel et la terre, pas un i, pas un point sur l'i, ne passera de la Loi, que tout ne soit réalisé. Et ailleurs, en d'autres termes: J'aurais encore beaucoup à vous dire, mais vous ne pouvez pas le porter à présent. Mais quand il viendra, lui, l'Esprit de vérité, il vous introduira dans la vérité tout entière, car il ne parlera pas de lui-même, mais ce qu'il entendra, il le dira et il vous dévoilera les choses à venir. (Mt 5, 17-18; Jn 16, 12-13) $)^{25}$.

Ajoutons que la série de prophéties des tribulations de la fin des temps, émises par Jésus lui-même (surtout en Mt 24 // Mc 13 // Lc 21), atteste éloquemment qu'il ne peut avoir accompli ce qu'il annonce luimême pour un futur lointain, et qui, à ce jour, ne s'est pas encore réalisé.

\subsection{Apocatastase et retour d'Élie}

Une autre manière d'aborder une «christologie du non-accomplissement » consiste à examiner attentivement le rapprochement opéré par les Évangiles entre Jean le Baptiste et Élie. On sait que, pour le judaïsme, la venue du Messie doit être précédée par le retour de ce prophète jadis enlevé au ciel (2 R 2). Il s'agit d'un dogme fondamental de la foi juive, puisque l'annonce en figure dans un oracle du prophète Malachie: "Voici que je vais vous envoyer Élie le prophète, avant que n'arrive le Jour de l'Eternel, grand et redoutable. Il ramènera le cœur des pères vers leurs fils et le cœur des fils vers leurs pères, de peur que je ne vienne frapper le pays d'anathème.» (Ml 3,23-24) L'un des passages les plus mystérieux pour certains, et irritants pour d'autres, est l'affirmation abrupte de Jésus concernant le retour d'Élie:

Et les disciples lui posèrent cette question: "Que disent donc les scribes, qu'Élie doit venir d'abord?» Il répondit: "Oui, Élie doit venir et tout réaliser [ou "remettre en état", verbe grec: apokathistanai], mais je vous le dis, Élie est déjà venu, et ils ne l'ont pas reconnu, mais l'ont traité à leur guise. De même le Fils de l'homme aura lui aussi à souffrir d'eux ». Alors les disciples comprirent que ses paroles concernaient Jean le Baptiste. (Mt 17,10-13)

25. MAHÈQRA, "La "génétique" divine », dans Le Royaume qui vient, ch. 6, $\mathbb{S}$ 5-6, en ligne sur $<$ www.rivtsion.net/documents/showthread.php ?s=\&threadid=2530>. 
On notera le parallèle que fait Jésus entre le sort de Jean le Baptiste et le sien. Le propos n'est pas anodin, mais il n'est pas possible de l'approfondir ici ${ }^{26}$. Remarquable est le fait qu'immédiatement après avoir été admis dans l'intimité surnaturelle de la «transfiguration» de Jésus, au Tabor, les disciples se réfèrent à leurs scribes pour vérifier si Jésus est bien le Messie (voir Mt 17,10), puisque le retour d'Élie, qui doit précéder l'avènement du Messie, selon la tradition juive, n'a pas encore eu lieu.

Dans un autre passage évangélique, l'affirmation de l'identité Élie/ Jean le Baptiste est nuancée d'un cum grano salis significatif, d'autant qu'elle se conclut par un leitmotiv qu'on ne trouve que dans les paraboles: "Et lui, si vous voulez bien l'admettre [ei thelete dexasthai], il est cet Élie qui doit venir. Que celui qui a des oreilles entende!» (Mt 11,14-15) Mais la plus sérieuse objection contre le bien fondé de cette équivalence entre Élie et Jean le Baptiste est la dénégation de ce dernier. L'Évangile la relate en ces termes: "Qu'es-tu donc?", lui demandèrent-ils. "Es-tu Élie ?" Il dit: "Je ne le suis pas"." (Jn 1,21)

Pourtant, aujourd'hui encore, une immense majorité de chrétiens croient, sans hésitation, que Jean le Baptiste était Élie et qu'il ne faut plus attendre la venue eschatologique de ce dernier.

Or, la position du judaïsme, à propos du rôle eschatologique d'Élie, est claire et sans problème. Le Messie étant encore à venir, son précurseur et coadjuteur, Élie, l'est aussi. C'est pourquoi la coutume pieuse veut qu'on laisse la porte ouverte lors de la célébration du Séder de Pesah, au cours duquel on remplit même un verre pour Élie (cos eliahou), ce dernier étant susceptible de venir à l'improviste. Et au terme du Shabbat, on chante pour hâter sa venue: "De mémoire bénie et de bon augure, qu'Elie le prophète (ter) vienne à nous promptement avec le Messie, fils de David ${ }^{27}$."

26. J'ai traité en détail de cette question dans M. Macina, «Jean le Baptiste était-il Élie ? Examen de la tradition néotestamentaire ", Proche-Orient Chrétien, 34 (1984) p. 209-232; cette revue étant quasi introuvable, j'ai mis en ligne le texte de cet article, à l'adresse suivante: <www.rivtsion.net/documents/showthread.php ?s=\&threadid $=2652>$.

27. "Zakhur le-tov, beSiman tov Eliyahu Ha-navi, Eliyahu Ha-navi - Eliyahu Ha-navi bi-mhera yavo' 'eleinu 'im mashiah ben-David." Cantique qui, selon certains rituels, ouvre les prières de la havdalah, ou séparation entre le temps sacré du Shabbat et celui des jours ordinaires de la semaine. Je suis ici J.-E. CHARBIt, dir., 
Précisons enfin, sans pouvoir nous étendre ici sur ce point qui mérite examen, qu'un nombre considérable de Pères de l'Église ont exprimé leur foi en un retour d'Élie, avec cette nuance apologétique de taille, toutefois, que, selon plusieurs d'entre eux, le prophète aura pour mission de convertir le peuple juif à la foi au Christ avant que ce dernier ne vienne sur les nuées du ciel ${ }^{28}$.

\section{L'État d'Israël: fait politique sans rapport avec l'histoire du salut, ou «prémices de l'émergence de la rédemption d'Israël»?}

Il n'échappera à personne que cette problématique est sans doute la plus controversée, voire la plus explosive, des quatre ici proposées. Qu'il soit bien clair cependant, que le débat envisagé sur ce thème n'a aucune perspective politique. Malheureusement, l'escalade meurtrière, qui a rendu inexpiable le conflit pour la terre entre Israéliens et Palestiniens ${ }^{29}$,

Rituel de Prières, rite sépharade, éd. bilingue, Patạ Eliyahou, ouvrage publié avec le concours du Centre Rambam, etc., Paris, Colbo, 1997, p. 285, 289s.

28. Voir M.R. Macina, «Le rôle eschatologique d'Élie le Prophète dans la conversion finale du peuple Juif », Proche-Orient Chrétien, 31 (1981) p. 71-99. Sur Élie, en général, chez les Pères, l'ouvrage de référence est sans conteste la somme réalisée par sœur E. Рогіот, Les prophètes Élie et Elisée dans la littérature chrétienne ancienne, Paris, Brepols, 1997.

29. Rappelons que les premiers sionistes vivaient en relativement bonne entente avec les autochtones arabes qu'on n'appelait pas encore Palestiniens, et que tant des idéologues du mouvement sioniste qu'un philosophe aussi considérable que Buber étaient de chauds partisans de la cohabitation fraternelle avec les Arabes. Voir M. Buber, Une terre et deux peuples. La question judéo-arabe / textes réunis et présentés par P. Mendes-Flohr, trad. de l'allemand par D. Miermont et B. Vergne, Paris, Lieu Commun, 1985 (allemand 1983). Mais ce que les Arabes vivant en Palestine - comme d'ailleurs la quasi-totalité des Arabes dans le monde - rejetaient sans compromis était l'établissement d'un État souverain non arabe en Palestine, considérée par eux comme une terre définitivement musulmane. Plus tard, l'émergence du sentiment nationaliste palestinien rendit le conflit inévitable. La question palestinienne est donc au cœur de l'histoire de l'État juif. De très nombreux ouvrages, israéliens et arabes, sont consacrés à ce sujet et à d'autres thèmes connexes. Brève sélection: A.W. Kayyali [auteur palestinien], Histoire de la Palestine, 1896-1940 / trad. par A.-M. Teeuwissen Abouelaazem, Paris, L'Harmattan, 1985 ; J.-P. Chagnollaud, Israël et les territoires occupés. La confrontation silencieuse, Paris, L'Harmattan, 1985; D. Ben Simon et E. Errera, Israéliens. Des Juifs et des Arabes, Paris, Complexe, 1989; G. Conm, Le Proche-Orient éclaté. 19561991 (Folio/Histoire), nouv. éd. aug. et mise à jour, Paris, Gallimard, 1991 (1983); 
rend pratiquement impossible d'éviter qu'une telle entreprise ne soit réputée remplie d'arrière-pensées sionistes, avec toute la charge péjorative que cet adjectif recèle dans l'esprit des ennemis irréductibles de ce fondement même de l'État juif qu'est le sionisme.

\subsection{Perspective juive}

Tout d'abord, il convient de préciser qu'au sein même du judaïsme, la controverse a longtemps fait rage autour de la question de l'opportunité de rassembler les Juifs sur une terre (fût-ce celle de leurs ancêtres) et d'y créer un État, dont nul n'ignorait qu'il serait laïc. Les religieux s'opposaient de toutes leurs forces à cette perspective, arguant principalement que seul le Messie pouvait rassembler les exilés sur la Terre sainte et y instaurer la royauté de Dieu ${ }^{30}$. Quant aux agnostiques et aux non pratiquants juifs, ils mettaient en garde contre le risque d'une reviviscence de l'antisémitisme, que ne manqueraient pas de susciter, selon eux, l'activisme et le propagandisme des sionistes, ou partisans du retour à Sion (nom poétique de Jérusalem). Et même de nos jours, en Israël, des Juifs de premier plan, religieux ou non, sont extrêmement critiques envers l'État d'Israël, précisément au nom de leur conception du sionisme ${ }^{31}$. À

E. Навів [Palestinien] et Y. Kaniuk [Israélien], La terre des deux promesses, Arles, Solin/Actes Sud, 1996; Israël. De Moïse aux accords d'Oslo (Points Histoire 251) [recueil d'articles repris d'un no spécial de L'Histoire, revus et complétés], Paris, Seuil, 1998; B. Khader, L'Europe et la Palestine: Des croisades à nos jours, Paris, L'Harmattan, 1999; A. Gresh, Israël, Palestine. Vérités sur un conflit, Paris, Fayard, 2001; "Le problème palestinien », dans Sionismes / textes réunis et présentés par D. Charbit, Paris, Albin Michel, 1998, ch. 19, p. 800-860; etc.

30. Lire à ce sujet le beau roman de H. Роток, L'élu, Paris, Calmann-Levy, 1969.

31. La bibliographie de cette controverse est très vaste. On se limitera ici à quelques titres, en commençant par ceux des «Nouveaux historiens ", ou d'auteurs qui traitent de leurs thèses. B. Morris, 1948 and After, Israel and the Palestinians, Oxford, Clarendon Press, $1994^{2}$ (1990). U. Ram, «Mémoire et identité: sociologie du débat des historiens en Israël », dans F. Heymann et M. АвітвоL, dir., L’historiographie israélienne aujourd'hui, Paris, CNRS, 1998, p. 198-243, qui donne une bibliographie quasi exhaustive à cette date. Ce précieux volume contient également d'autres contributions incontournables: D. Porat, «Un problème historiographique : l'attitude de David Ben Gourion vis-à-vis des Juifs d'Europe pendant la Shoah », p. 111130; B. Morris, "La nouvelle historiographie: Israël confronté à son passé», p. 131-180; I. BARTAL «La révolution tranquille: entre mythe et science», p. 181195. Les réactions à ce nouveau courant et spécialement les réfutations des thèses 
ce propos, l'une des questions les plus chaudement débattues est celle de la prétendue dépossession, par les Israéliens, de territoires réputés palestiniens, et de son corollaire: le problème des réfugiés. Un très grand nombre de livres et surtout d'articles incriminent Israël de manière tellement passionnelle et injuste que les quelques rares mises au point impartiales, ou favorables à Israël sont submergées et quasiment inconnues du grand public ${ }^{32}$.

de B. Morris, père de cette nouvelle historiographie sont nombreuses. Quelques titres: E. Karsh, Fabricating Israeli History: The "New Historians", éd. rév., London - Portland, Frank Cass, 20002 (1997); E. NAvon, «Les points de révision de l'histoire du sionisme: thèses en présence et récupération révisionniste ", Conférence du Bnaï Brith, à Yad Vashem, décembre 2001 (<www.upjf.org/documents/ showthread.php ?s=\&threadid=1703>).

32. Signalons, entre autres: Eliezer Schweid, Israel at the Cross Roads, Jewish Publication Society, Philadelphia, 1973; J. Peters, From Time Immemorial. The Origins of the Arab-Jewish Conflict Over Palestine, New York - Cambridge - Philadelphia - San Francisco - London - Mexico City - Sao Paulo - Singapore - Sydney, J. Kap Publishing, 1984 (nombreuses réimpressions depuis), ouvrage passionné et souvent passionnel, à utiliser avec précaution, en particulier en raison de ses à peu près historiques et de son utilisation, pas toujours fiable, de sources empruntées à des ouvrages de seconde main. A.L. Avneri, Claim of Dispossession: Jewish LandSettlement and the Arabs 1878-1948 / trad. par le Kfar-Blum Translation Group, New Brunswick, USA - London, UK, Transaction Books, 1984 (hébreu 1980) (de loin le meilleur ouvrage et le plus fiable sur la question: l'auteur utilise massivement les sources arabes, israéliennes et anglaises, dont il maîtrise les langues originales, c'est un ouvrage incontournable, quoique de lecture aride et difficile). E. Karsh, The Arab-Israeli Conflict. The Palestine War 1948, Oxford, UK, Ospray Publishing, 2002; M.G. BARD, Mythes et réalités des conflits du Proche-Orient I trad. et adapt. françaises par L. Messika, Paris, Raphaël, 2002; A. Dershowitz, The Case for Israel, Hoboken, New Jersey, John Wiley \& Sons, 2003 ; etc. Consulter également les articles suivants: G. ADLER, "Aspects historiques et légaux du conflit Juifs-Arabes israélo-palestinien », en ligne sur <www.upjf.org/documents/ showthread.php ?s=\&threadid=2128>; D. GoLD, «Des "Territoires occupés" aux "Territoires disputés" ", <www.upjf.org/documents/showthread.php ?s=\&threadid =1659>; Y. Bin Noun, "Le mythe palestinien", <www.upjf.org/documents/ showthread.php?s=\&threadid=34>; Palestinian Authority and P.L.O. NonCompliance with signed agreements and commitments: A record of bad faith and misconduct. Complete text of Barak Government "white paper" on PA/PLO noncompliance (novembre 2000), en ligne sur <http://gamla.org.il/english/feature/ intro.htm> et en français ( Le Livre blanc du conflit palestino-israélien») sur $<$ www.upjf.org/documents/showthread.php ?s=\&threadid=53>; C. Delacampagne, 
Il ne faudrait cependant pas croire que l'aspiration des Juifs à revenir sur la terre des ancêtres date des débuts du sionisme politique (vers la fin du XIX ${ }^{e}$ s.). Depuis la fin de son existence nationale en Terre sainte, le peuple juif dispersé dans ses lieux d'exil par toute la terre n'a jamais cessé d'espérer un retour dans sa patrie et a exprimé cette nostalgie dans sa prière et sa littérature. À la fin du repas annuel de la Pâque, les Juifs du monde entier répètent le vœu: "L'an prochain à Jérusalem », et lors des mariages juifs, le fiancé récite: "Si je t'oublie, Jérusalem, que ma droite se dessèche» (Ps 137,5). Rappelons que le sionisme est la forme politique qu'a prise le mouvement de restauration de l'autodétermination du peuple juif dans sa patrie et le rétablissement de la souveraineté juive dans le pays d'Israël ${ }^{33}$. Le passage suivant de la Déclaration d'Indépendance d'Israël est significatif à ce sujet: «Nous lançons un appel au peuple juif de par le monde à se rallier à nous dans la tâche d'immigration et de mise en valeur, et à nous assister dans le grand combat que nous livrons pour réaliser le rêve poursuivi de génération en génération: la rédemption d'Israël ${ }^{34}$.»

«Rédemption d'Israël » : formulation audacieuse. On la trouve, sous une forme encore plus forte et poétique - «re'shit tsmiḩat ge'ulatenu»

«À un ami palestinien ", <www.upjf.org/documents/showthread.php ?s=\&threadid =1759>; COORDinATION INTERCOMMUNAUTAIRE CONTRE L'ANTISÉMitisme ET LA Diffamation (CICAD), «FAQ - Questions et Réponses sur le conflit israélo-arabe» (mars 2002), <www.upjf.org/documents/showthread.php ?s=\&threadid=33>; M. Macina, "Le Contentieux israélo-palestinien, sa genèse, ses interrogations, ses impasses » (mai 2003), <www.upjf.org/documents/showthread.php ?s=\&threadid =4431 >; J. Fishman, "Guerre populaire de l'OLP - Réponse inadéquate d'Israël ", $<$ www.upjf.org/documents/showthread.php ?s=\&threadid=5443>.

33. La bibliographie du sujet est pléthorique. Voici quelques ouvrages de référence: Z. Sternhell, Aux origines d'Israël. Entre nationalisme et socialisme, Paris, Fayard, 1996 ; C. Klein, La démocratie d'Israël, Paris, Seuil, 1997; Sionismes / textes réunis et présentés par D. Charbit, Paris, Albin Michel, 1998; A. Michel, Racines d'Israël, Paris, Autrement, 1998; G. Bensoussan, Une histoire intellectuelle et politique du sionisme (1860-1940), Paris, Fayard, 2002. Sur l'histoire politique de la Palestine aux XIX ${ }^{\mathrm{e}}$ et $\mathrm{Xx}^{\mathrm{e}}$ siècles, consulter: H. LAurens, Le Retour des exilés. La lutte pour la Palestine de 1869 à 1997, Paris, R. Laffont, 1998. Et, pour les lecteurs pressés: C. Franck et M. Herszlikowicz, Le Sionisme (Que sais-je ? 1801), Paris, Presses Universitaires de France, 1988; A. Boyer, Les origines du sionisme (Que sais-je? 2397), Paris, Presses Universitaires de France, 1988; etc.

34. Texte intégral accessible en ligne sur <www.upjf.org/documents/showthread.php ?s $=\&$ threadid $=3356>$. 
("prémices de l'émergence de notre rédemption») — dans la Prière pour l'État d'Israël, qui figure dans presque tous les recueils de prière ${ }^{35}$. Elle fit scandale et a encore ses détracteurs juifs, religieux aussi bien que non religieux, y compris chez les plus sionistes d'entre eux, tel Y. Leibovitz, aujourd'hui disparu:

Ce qui éveille en moi un sentiment proche du dégoût, c'est d'entendre, non seulement le jour de l'indépendance, mais chaque Shabbat, la prière pour le salut de l'État - dont on dit qu'il est «le début de notre rédemption ». Cet État n'a été créé ni à cause du judaïsme, ni dans l'intérêt du judaïsme. Il est le cadre de l'indépendance nationale du peuple juif. De là à en faire "le début de notre rédemption ", c'est profaner le concept de rédemption ${ }^{36}$.

Plus modérée dans son expression, et se plaçant davantage sur le terrain de l'éthique que sur celui de la théologie, est la position du

35. La prière est ainsi formulée:

Notre Père qui es dans les cieux, Rocher d'Israël et son Rédempteur, bénis l'État d'Israël, début de l'émergence de notre rédemption [re'shit tsmihat ge'ulatenu]. Mets-le à l'abri sous les ailes de Ton amour. Étends sur lui la tente de Ta paix; envoie Ta lumière et Ta vérité à ses dirigeants, à ses ministres et à ses conseillers, et assiste-les de Ton bon conseil. Affermis les mains des défenseurs de notre terre sainte et accorde-leur, ô notre Dieu, le salut et la couronne de la victoire. Établis la paix sur la terre, et emplis ses habitants d'une joie éternelle. Et prends soin de nos frères, toute la maison d'Israël, dans tous les pays où ils sont dispersés. Faisles vite marcher, la tête haute [voir Lv 26,13] vers Sion, Ta ville, et vers Jérusalem, le lieu où réside Ton nom, comme il est écrit dans la Torah de Moïse, Ton serviteur: "Quand tu serais banni à l'extrémité des cieux, de là-bas, l'Eternel ton Dieu te rassemblera, et de là-bas, Il viendra te prendre pour te ramener au pays dont tes pères ont hérité, afin que tu en hérites, et que tu y sois heureux, et que tu t'y multiplies plus que tes pères." [Dt 30,4-5]. Dispose notre cœur à aimer et révérer ton nom, et à observer tous les préceptes de Ta Torah. Manifeste-Toi dans la gloire de Ta majesté à tous les habitants de Ton monde. Et que tout ce qui respire proclame: L'Eternel, le Dieu d'Israël est roi; «et Sa royauté s'étend sur tout» [Ps 103,19]. Amen!

Sur cette prière, voir l'article utile du rabbin E. Snitkoff, "Praying the Welfare of the State of Israel », en ligne sur <www.myjewishlearning.com/holidays/Modern_ Holidays/Yom_Haatzmaut/Prayer.htm>.

36. Y. Leibovitz, Israël et le judaïsme. Ma part de vérité, Paris, Desclée de Brouwer, 1993, p. 41. Exposé plus complet de ses conceptions: idem, Judaïsme peuple juif et État d'Israël / trad. par G. Roth (Thor), Paris, J.-C. Lattès, 1985 (hébreu 1976). 
regretté Ephraïm Urbach ${ }^{37}$. En voici un bref résumé, emprunté à un spécialiste chrétien :

E. Urbach rappelle [...] que la formule «Début de la Rédemption» a été employée par le Talmud pour désigner les guerres qui précèdent la rédemption et que, si "nous sommes encore dans les guerres ", personne ne peut dire que ces guerres soient celles qu'annonce le Talmud et qui précèdent la rédemption messianique [...]. Je cite ici les dernières lignes de son examen de la «Rédemption selon les Sages...": "Je n'aime pas me servir de la formule "Début de la croissance de notre Rédemption", mais je voudrais dire que nous devons voir notre situation comme une grande réalisation qui ouvre et qui donne la possibilité de continuer, si nous ne faisons pas abstraction de la réalité, et si nous ne nous voyons pas comme un peuple élu selon une conception déformée du concept de l'élection. Nous devons nous rappeler que le processus de la rédemption dans lequel nous nous trouvons est encore ce qui se déroule dans le monde du mérite et du devoir, de la responsabilité et aussi de l'attente d'une rédemption supplémentaire $^{38}$ ».

Un dernier mot sur la formule «début de la Rédemption». Il ne faudrait pas imaginer qu'il s'agit d'une innovation sioniste basée sur un

37. E.E. Urbach, «Hag'ullah bi-tefisat hazal u-meora'ot yameinu » [ "La Rédemption selon les Sages et les événements de notre temps»], dans 'Al tsionut we-yahadut iyyunim u-massot [Sur le sionisme et le judaïsme - Études et Essais], Jérusalem, 1985, p. 49-52. Rappelons que ce grand savant israélien a gratifié la recherche d'un important ouvrage de référence: E.E. Urbach, Les Sages d'Israël, conceptions et croyances des maîtres $d u$ Talmud / trad. par M.-J. Jolivet, Paris, Cerf - Verdier, 1996 (hébreu 1969). Son ch. 17 (p. 669-711) est entièrement consacré à la théologie de la notion de Rédemption dans la littérature rabbinique.

38. Frère P. Lenhardt, «La fin du sionisme? », Sens, 3 (2004) p. 131. Long (p. 99-138) mais important article dont le thème est beaucoup plus large que ne le suggère son titre. On y trouvera en particulier des analyses liturgiques et exégétiques dont les non-spécialistes ignorent tout. Elles sont vulgarisées avec bonheur, dans cet article d'un auteur qui maîtrise les sources juives, dont il est un des rares spécialistes catholiques francophones. C'est le lieu de saluer ici le mérite de la revue Sens, soustitrée «Juifs et Chrétiens dans le monde d'aujourd'hui ». Elle est publiée par l'Amitié judéo-chrétienne de France (AJCF) - fondée en 1948, sise 60, rue de Rome 75008 Paris - et dirigée de main de maître par le professeur Yves Chevalier. La collection, qui compte des centaines de numéros, est une mine d'articles incontournables pour quiconque veut suivre les progrès de "l'enseignement de l'estime ", dont Jules Isaac fut l'un des plus éminents pionniers, et sous le haut le patronage duquel, conjointement avec Edmond Fleg, s'est placée l'AJCF. 
syncrétisme douteux entre religion et chose politique, et assorti de conceptions bibliques de nature fondamentaliste - bien que certains, Juifs autant que chrétiens, utilisent, souvent et sans discrimination, cette formule à l'appui de leurs vues hasardeuses sur l'imminence de l'approche de la «fin des temps». En fait, l'expression est tirée du Talmud de Babylone (Megillah 17b), et se dit, en araméen: athalta di-ge'ullah. Pierre Leenhardt a fort opportunément traduit le commentaire, que fait, de cette expression, le grand commentateur médiéval de la Bible, Rachi (1040-1105):

Bien que cette Rédemption ne soit pas la Rédemption de l'Exil, mais celle par laquelle nous sommes rédimés des détresses qui viennent sur nous sans cesse - nous voyons en effet que la bénédiction du Rassemblement [des Exilés, $10^{\mathrm{e}}$ Bénédiction], celle de la Construction de Jérusalem [14 ${ }^{\mathrm{e}}$ bénédiction], et celle du «Rejeton de David» [15e bénédiction] sont des bénédictions ayant chacune leur valeur propre indépendamment de cette Rédemption [de la $7^{\mathrm{e}}$ bénédiction] -, bien qu'il en soit ainsi, du moment que le nom de Rédemption lui est appliqué, [nos Maîtres] l'ont établie comme septième bénédiction ${ }^{39}$.

\subsection{Perspective chrétienne}

Du point de vue chrétien, la question de l'État d'Israël peut être appréhendée sous un angle théologique ou éthique. Quelques rares textes catholiques ne font, il faut bien l'avouer, qu'effleurer le sujet, avec embarras et souci visible de ne pas tomber sous le coup du soupçon de soutien à Israël. Comme cet extrait des Notes pour une correcte présentation des Juifs et du judaïsme, qui prend savamment ses distances par rapport à ce problème épineux:

39. Lenhardt, «La fin du sionisme? ", p. 120-121. Rachi est l'acronyme du plus célèbre des commentateurs médiévaux de la Bible et du Talmud: RAbbi CHlomo Itshaki, né à Troyes (1040-1105). Ses gloses sont simples et brèves, et n'ont pour but que d'éclairer le sens littéral du texte. Aucun juif cultivé n'étudie la Torah ou le Talmud sans consulter Rachi. Pour une brève initiation, et entre autres: [ouvrage collectif,] Rachi, Paris, Service technique pour l'éducation, 1974; S. SchwarzFuchs, Rachi de Troyes, Paris, Albin Michel, 1991. Plus érudit: G. Sed-Rajna, dir., Rashi 1040-1990. Hommage à Ephraïm E. Urbach (Congrès européen des Etudes juives), Paris, Cerf, 1993. 
Les chrétiens sont invités à comprendre cet attachement religieux, qui plonge ses racines dans la tradition biblique, sans pour autant faire leur une interprétation religieuse particulière de cette relation [...]. Pour ce qui concerne l'existence de l'État d'Israël et ses options politiques, celles-ci doivent être envisagées dans une optique qui n'est pas en elle-même religieuse, mais se réfère aux principes communs du droit international ${ }^{40}$.

Le premier texte théologique d'Église qui aborde le problème et, sauf erreur, le seul de cette nature, est le document intitulé L'attitude des chrétiens à l'égard du judaïsme. Orientations pastorales du Comité épiscopal pour les relations avec le judaïsme (France 1973). On peut y lire, entre autres:

Il est actuellement plus que jamais difficile de porter un jugement théologique serein sur le mouvement de retour du peuple juif sur «sa» terre. En face de celui-ci, nous ne pouvons tout d'abord oublier, en tant que chrétiens, le don fait jadis par Dieu au peuple d'Israël d'une terre sur laquelle il a été appelé à se réunir (cf. Genèse 12, 7; 26, 3-4; Isaïe 43, 5-7; Jérémie 16, 15; Sophonie 3, 20)...

[...] C'est une question essentielle, devant laquelle se trouvent placés les chrétiens comme les juifs, de savoir si le rassemblement des dispersés du peuple juif, qui s'est opéré sous la contrainte des persécutions et par le jeu des forces politiques, sera finalement ou non, malgré tant de drames, une des voies de la justice de Dieu pour le peuple juif et, en même temps que pour lui, pour tous les peuples de la terre. Comment les chrétiens resteraient-ils indifférents à ce qui se décide actuellement sur cette terre ${ }^{41}$ ?

Par ailleurs, au moins deux théologiens français ont traité, de manière particulièrement honnête et courageuse, la difficile question du sens, pour la théologie chrétienne, du retour des Juifs dans leur terre: le père Michel Remaud, directeur de l'Institut français Albert-Decourtray d'études juives à Jérusalem ${ }^{42}$, et le père Jean Dujardin, qui fut secrétaire du Comité épiscopal français pour les relations avec le judaïsme, de 1987

40. Commission du SAint-Siège, Notes pour une correcte présentation, p. 218.

41. CONFÉREnce Épiscopale française, L'attitude des chrétiens à l'égard du judaïsme. Orientations pastorales du Comité épiscopal pour les relations avec le judaïsme (France 1973), section 5, $\mathbb{S}$ e); accessible en ligne sur <www.chretiens-et-juifs.org/ article.php ?voir[]=1721\&voir[]=1669>.

42. Voir leur site Web: <www.afiq.net/institut/index.htm>. 
à 1999. L'un et l'autre ont consacré plusieurs pages de leurs ouvrages respectifs à cette question ${ }^{43}$.

Dans un chapitre qu'il a intitulé «Israël et sa terre ${ }^{44}$ ", Michel Remaud procède à un survol de l'origine divine du don de la terre et des avatars de la relation d'Israël à cette terre, dont la permanence dépend de la fidélité du peuple à son Dieu et aux commandements qu'il lui a donnés. Il précise toutefois:

La nécessité de fidélité à l'alliance ne contredit pas le caractère irrévocable du don: si le péché, au témoignage de l'Écriture, entrâne l'exil, le retour ne dépend ni exclusivement ni même premièrement de la conversion. Les prophètes mettent au contraire au premier plan l'initiative gratuite de Dieu, qui ramène Israël sur sa terre par fidélité à lui-même et qui change le cœur de l'homme (cf. Ezéchiel 36,16-38; Amos 9,8-15, etc.) [...]. Ajoutons que les perspectives universalistes ouvertes par les oracles eschatologiques des prophètes ne mettent pas un terme à la relation d'Israël à sa terre: à la fin des temps, les nations elles-mêmes ramèneront à Sion les exilés du peuple élu (Isaïe 66,18-21... $)^{45}$.

Après avoir constaté et expliqué la rareté du thème de la terre dans le Nouveau Testament, M. Remaud met en garde contre la tentation d'en tirer la conséquence

... que ce thème n'a plus d'importance dans l'économie instaurée par la résurrection de Jésus, que toutes les promesses trouvent dans le Christ leur accomplissement, et que le don de la terre n'a plus désormais qu'une signification spirituelle [et] que le rassemblement du peuple juif qui se réalise aujourd'hui sur la terre de la Bible doit être interprété en termes purement profanes $^{46}$.

43. Il s'agit respectivement de M. Remaud, Chrétiens et Juifs entre le passé et l'avenir, Bruxelles, Lessius, 2000, et de J. Dujardin, L'Église catholique et le peuple juif. Un autre regard, Paris, Calmann-Lévy, 2003.

44. Remaud, Chrétiens et Juifs, ch. 8, p. 113-128. Voir aussi, du même auteur: Israël, Serviteur de Dieu, Paris, Cerf, 1983 (réédition CCEJ, 1996); À cause des pères. Le "mérite des pères" dans la tradition juive, Louvain, Peeters, 1997; Évangile et tradition rabbinique, Bruxelles, Lessius, 2003; Le judaïsme (Que penser de? 55), Namur, Fidélité, 2003; Le Midrash (Supplément au Cahier Évangile 82), Paris, 1992, en collaboration avec E. KetTerer; etc.

45. Remaud, Chrétiens et Juifs, p. 115-116.

46. Remaud, Chrétiens et Juifs, p. 117. 
Après avoir reconnu que «la théologie chrétienne est presque muette sur ce sujet», il cite ce propos d'un autre théologien: "Rien dans la théologie ou l'histoire chrétienne n'a fourni à l'Église les moyens conceptuels de se trouver en accord avec la nouvelle réalité, ce qui a fortement contribué au résultat contraire ${ }^{47}$. " Retenons encore cette réflexion importante de M. Remaud, qui figure dans un chapitre qu'il faut lire dans son intégralité, tant il est riche sur le plan de la théologie biblique comme sur celui de la théologie d'Israël:

À moins d'affirmer que le lien entre le peuple juif et la Bible serait définitivement rompu — opinion dont le moins que l'on puisse dire est qu'elle ne serait pas en accord avec les affirmations du dernier concile - , on voit mal comment on pourrait nier tout rapport entre le rassemblement partiel du peuple juif sur la terre de ses ancêtres et les promesses bibliques. Le lecteur attentif de l'Écriture pourra remarquer d'ailleurs, que ce sont les mêmes textes qui annoncent le renouvellement de l'alliance et la fin de la dispersion du peuple juif. Le chapitre 36 d'Ézéchiel, qui est une des principales références chrétiennes sur la nouvelle alliance, mêle intimement cette promesse à celle du retour d'Israël sur sa terre, au point qu'on ne peut dissocier les deux thèmes sans mutiler l'Écriture elle-même. Le retour y apparait comme le signe de l'accomplissement des promesses eschatologiques: "Je vous prendrai d'entre les nations, je vous rassemblerai de tous les pays et je vous ramènerai sur votre sol. Je ferai de vous une aspersion d'eau pure et vous serez purs [...]. Je vous donnerai un cœur neuf et je mettrai en vous un esprit neuf...» (Ez 36, 24-28). On ne saurait donc, sans arbitraire, interpréter certains versets ou fragments de versets au sens littéral et allégoriser les autres, alors que le charnel... est le signe du spirituel. Et si l'on objecte que la résurrection de Jésus rend désormais inutile toute autre forme d'accomplissement, ou que la réalisation des promesses bibliques, après la proclamation de l'Évangile, ne serait qu'une régression vers le moins parfait, on pourra toujours répondre que Dieu a le pouvoir et la liberté de «faire ceci sans omettre cela» (cf. Matthieu 23,23) ${ }^{48}$.

Quant au père Jean Dujardin, le contenu du long chapitre de son ouvrage consacré au «retour du peuple juif sur la terre d'Israël ${ }^{49}$ » se

47. Remaud, Chrétiens et Juifs, p. 117. L'auteur cité est A. Davies, «L'attitude à l'égard d'Israël: le peuple, la terre, l'État. 2) Point de vue d'un chrétien ", Concilium, 98 (1974) p. 95.

48. Remaud, Chrétiens et Juifs, p. 119-120.

49. Dujardin, L'Église catholique, ch. 4, p. 214-242. 
ressent de sa formation d'historien. On n'y trouve donc pas les perspectives exégétiques, voire midrashiques, du père Remaud, qui n'est pas seulement un théologien, mais maîtrise également les sources juives ${ }^{50}$. Par contre, on y découvre des détails significatifs qui jettent une lumière instructive sur certains aspects, trop peu soulignés, voire quasiment inconnus, des chercheurs, de la gêne et de la réticence catholiques face à la renaissance nationale du peuple juif. Tel, entre autres, le développement suivant :

Disons-le clairement: l'Église ne s'attendait pas à une telle éventualité et la renaissance de l'État d'Israël l'a surprise dans sa vision des Lieux saints et du Proche-Orient. Elle s'était habituée [...] à l'idée que le judaïsme n'était plus qu'une religion, que les juifs formaient encore, ici et là, des groupes ethniques historico-culturels, mais qu'en tout état de cause, le lien avec la terre d'Israël n'était plus qu'un élément du folklore religieux [...] les chrétiens pensaient que la condition juive était, théologiquement, la condition d'un peuple dispersé [...]. Aussi pour reprendre en compte l'existence juive sur la Terre d'Israël, il fallait que l'Église remette en question cette interprétation théologique, certes jamais officiellement élaborée mais constamment présente dans les esprits ${ }^{51}$.

On trouve encore, dans l'ouvrage du père Dujardin, ce rappel du refus opposé à Herzl par le cardinal Merry del Val, et surtout par Pie X:

Nous ne pouvons empêcher les Juifs de se rendre à Jérusalem, mais nous ne pouvons en aucun cas lui accorder notre soutien. Même si elle n'a pas toujours été sainte, la Terre de Jérusalem a été sanctifiée par la vie de JésusChrist. En tant que chef de l'Église, je ne peux vous dire autre chose: Les Juifs n'ont pas reconnu notre Seigneur, aussi, nous ne pouvons pas reconnaître le peuple juif [soulignement du père Dujardin] ${ }^{52}$.

50. Précisons que l'ouvrage de M. Remaud, À cause des pères, est la version livresque de son doctorat, dont l'érudition et la profondeur d'analyse témoignent de sa familiarité, impressionnante chez un religieux catholique, avec la littérature rabbinique.

51. Dujardin, L'Église catholique, p. 224.

52. Dujardin, L'Église catholique, p. 224-225. La citation de Pie X figure dans M. Lowenthal, dir., The Complete Diaries of Theodor Herzl, London, Herzl Press, 1960, vol. 4, p. 1603. Voir aussi l'important article de F.M. Perko, s.j., «Toward a "Sound and Lasting Basis": Relations between the Holy See, The Zionist Movement, and Israel, 1896-1996 ", Israel Studies, 2/1 (1997), aussi disponible en français : "Vers une "base saine et durable" : Relations entre le Saint-Siège, le mouvement sioniste et Israël de 1896 à 1996 » / trad. par J. Dumortier, en ligne sur <www.upjf.org/documents/showthread.php ?s=\&threadid=5608>. 
Optimiste, le père Dujardin estime que le contenu de l'accord fondamental conclu entre le Saint-Siège et l'État d'Israël va plus loin que la nature intrinsèque - diplomatique et politique - de ce document. Il y décèle «au moins une portée éthique ». À l'appui de sa vue personnelle, il se réfère à un communiqué du Comité épiscopal français de décembre 1993, qui «parle de légitimité du retour du peuple juif sur la Terre d'Israël ». Mais, de son propre aveu, la conséquence optimiste qu'il en tire ne figure pas dans cet accord fondamental:

S'ouvre alors une interrogation plus religieuse que l'accord n'évoque pas, mais qui est en toile de fond. Pendant des siècles, la pensée la plus commune dans l'Église a donné une interprétation religieuse de la dispersion juive, elle y a vu la conséquence d'une faute théologique. Elle a aussi donné de cette dispersion une interprétation morale: une punition permanente pour le peuple juif. Dans ce contexte, l'accord fondamental doit être lu par les Juifs au minimum comme l'assurance que l'Église a enfin «tourné le dos» à cette interprétation tragique et lourde de conséquence [...] elle donne au moins à penser indirectement qu'ayant renoncé à l'interprétation négative, il est légitime, du point de vue éthique, d'y voir la réalisation d'une certaine justice... ${ }^{53}$

Enfin, à propos du silence (relatif) du Nouveau Testament sur le rôle de la terre dans l'économie nouvelle, inaugurée par le Christ, selon la foi chrétienne, le père Dujardin prend ses distances avec la conception traditionnelle selon laquelle il faut y voir le signe de "la caducité de l'enseignement de l'Ancien Testament sur ce point précis ». Son argumentation, même si elle n'est pas entièrement nouvelle - elle fait partie de l'argumentaire biblique d'un nombre non négligeable d'artisans du dialogue entre chrétiens et Juifs —, devrait devenir commune en milieu chrétien:

Les chrétiens, païens d'origine, auront à s'appuyer sur d'autres médiations de la promesse divine à partir du Christ et de l'Église. Mais cela ne signifie pas la négation du rôle de la terre pour le peuple d'Israël et l'importance des événements historiques le concernant qui s'y jouent. On le voit dans la scène de l'Ascension (Actes 1,6-7). À la question des disciples: "Seigneur, est-ce maintenant que tu vas restaurer la royauté en Israël ? » Jésus répond: «Il ne vous appartient pas de connaître les temps et les moments. » Jésus

53. Dujardin, L'Église catholique, p. 227. 
ne dit pas que la question est stupide [...]. Cela nous conduit à cette conclusion. Pas plus que la vocation permanente d'Israël n'a été abolie par l'Église, rien dans le Nouveau Testament ne nous permet de penser que le don de la Terre au peuple d'Israël a été annulé par Dieu ${ }^{54}$.

Quoi qu'il en soit de l'enjeu théologique de l'existence d'Israël, il n'en demeure pas moins qu'est posée là une interpellation éthique. Déjà, en 2001, dans un article consacré à l'isolement d'Israël et publié dans une revue bénédictine, j’y allais d'une réflexion en ce sens:

Dans l'esprit des pionniers juifs ${ }^{55}$, le sionisme apparaissait comme la seule réponse adéquate aux violentes persécutions antisémites auxquelles n'avaient mis un terme ni l'émancipation ni le loyalisme national dont les Juifs avaient pourtant fait la preuve dans tous les pays où ils s'étaient, dans l'ensemble, bien intégrés. Les théoriciens de ce mouvement étaient convaincus que leur peuple devait prendre en mains son destin politique et social, au lieu de subir la loi et les avanies des nations où il n'avait été, durant de longs siècles, qu'un hôte tout juste toléré, souvent humilié, menacé, spolié, voire mis à mort, et toujours contraint de composer et de ruser pour survivre et préserver ses acquis. À leurs yeux, seul un État fondé par des Juifs sur une terre juive, pouvait rédimer leur peuple, responsable, par veulerie ou résignation, de son image, alors universellement répandue, d'usurier ou de colporteur cruel et cupide. Qui eût pu prévoir que la piètre terre lointaine, qui n'était alors l'objet d'aucune revendication nationale, et dont on n'eût jamais imaginé qu'elle serait un jour disputée au peuple qui en était issu, deviendrait un piège pour les Juifs qui, las d'être les parias des nations, avaient cru - tragique naïveté ! - recouvrer leur dignité et gagner le respect de l'humanité en devenant enfin une nation comme les autres ${ }^{56}$ ?

Depuis, on le sait, les choses se sont envenimées au point que l'hostilité quasi universelle, dont est l'objet l'État d'Israël, ne peut plus être considérée honnêtement comme la conséquence d'une saine réaction de

54. Dujardin, L'Église catholique, p. 236-237.

55. Sur les débuts de l'installation des premiers sionistes en Terre sainte, lire le bref mais précieux ouvrage du regretté J.-M. Delmaire, De Jaffa jusqu'en Galilée. Les premiers pionniers juifs (1882-1904), Villeneuve-D'ascq (Nord), Presses Universitaires du Septentrion, 1999.

56. M.R. Macina, "Rester à part", ou "être mis à part" ? Les Juifs: une question pour les nations ", Revue de Ligugé, 295 (janvier 2001). Cet article est également disponible en ligne, à l'adresse suivante: <www.upjf.org/documents/showthread. php ?s=\&threadid $=3637>$. 
nations et de personnes sincèrement éprises de justice et scandalisées par les exactions de l'État juif. La violence, l'excès, la grossièreté, voire l'antisémitisme le plus abject des discours accusateurs, sans parler des crimes odieux dont est victime la population civile israélienne, trahissent la nature haineuse, perverse et, au mieux, irrationnelle de cette hostilité, à laquelle on a fort justement donné le nom d'antisionisme ${ }^{57}$. (Signalons au passage que, dans une déclaration conjointe faite à l'issue de la $18^{\mathrm{e}}$ rencontre du Comité International de Liaison entre Catholiques et Juifs, à Buenos Aires (5-8 juillet 2004), l'Église catholique vient de condamner l'antisionisme en ces termes: "Nous nous sentons encouragés par les fruits de nos efforts collectifs qui incluent la reconnaissance de la relation d'alliance unique et intacte entre Dieu et le peuple juif et le rejet total de l'antisémitisme sous toutes ses formes, y compris l'antisionisme comme manifestation plus récente de l'antisémitisme ${ }^{58}$.")

Le monde protestant n'est pas en reste, bien qu'il soit moins prodigue de déclarations en cette matière. Il est, en effet, traversé par des courants d'idées divergents et même antagonistes à propos de l'antisionisme. En témoigne un colloque, organisé le 2 mai 2004, par la Fédération Protestante, à Paris, en partenariat avec le Conseil Représentatif des Institutions juives de France, sur le thème "Juifs et Protestants aujourd'hui ». Entre autres interventions éclairantes, il convient de signaler une remarquable

57. L'antisionisme souvent considéré comme un sous-produit de l'antisémitisme - dont il n'est d'ailleurs pas toujours dénué, tant s'en faut —, diffère de lui, cependant, en ce qu'il se donne une justification que l'opinion publique considère comme honorable: la défense des droits légitimes du peuple palestinien, dont les droits les plus élémentaires apparaissent comme bafoués par un Israël puissant et intransigeant. L'étude de ce phénomène n'en est qu'à ses débuts et attend encore ses historiens. Les titres indiqués ici, ne constituent qu'un aperçu: P. Ginıewski, L'antisionisme, Bruxelles, Édition de la librairie encyclopédique, 1973; G.-E. Sarfati, L'antisionisme. Israël/Palestine aux miroirs de l'Occident, Paris, Berg International, 2002; S. Trigano, dir., Le Sionisme face à ses détracteurs, Paris, Raphaël, 2003 (voir une présentation de cet ouvrage en ligne sur <www.upjf.org/documents/showthread. php ? $\mathrm{s}=\&$ threadid $=4237>$ ). De très nombreux articles abordent ce thème avec plus ou moins d'objectivité et de compétence. On ne les recensera pas ici.

58. Rapport sur la 18 e rencontre du Comité International de Liaison entre Catholiques et Juifs - Buenos Aires, 5-8 juillet 2004 / trad. par C. Detienne, sur le site de l'Union des Patrons et des Professionnels Juifs de France (UPJF), à l'adresse suivante: <www.upjf.org/documents/showthread.php ?s=\&threadid=7031>. 
contribution de Florence Taubmann, pasteur à l'oratoire du Louvre ${ }^{59}$. Sa réflexion s'articule autour des différentes perceptions qui ont cours, dans le monde protestant, à propos du sionisme et du conflit palestinoisraélien :

(1) Un prosionisme religieux s'appuyant directement sur la Bible, et ayant, chez certains, une dimension eschatologique (le retour des juifs à Sion annonce la fin des temps et la révélation du Messie au monde entier, le Messie étant le Christ enfin reconnu), alors que, chez d'autres, il traduit seulement leur joie du retour du peuple de Dieu sur sa terre. (2) Un prosionisme politique, exprimant un soutien à Israël volontairement déconnecté de toute dimension religieuse, soulignant, entre autres choses, le bien-fondé de la création de l'État d'Israël à la suite des persécutions européennes et surtout de la Shoah, mais aussi la nature démocratique de cet État et son rôle potentiellement positif dans la région. (3) Une critique théologique du sionisme, affirmant que l'idée de terre sainte est étrangère à la théologie protestante: ce n'est pas dans un lieu et sur une terre donnés qu'on adore Dieu, mais en esprit et en vérité, le judaïsme doit donc être déconnecté du sionisme; la conférencière faisant remarquer que cette critique théologique du principe même du sionisme (retour sur cette terre-là) peut aller, dans certains cas, jusqu'à l'antisionisme. (4) Un antisionisme politique s'appuyant sur un engagement propalestinien, la compassion et l'engagement envers le peuple palestinien pouvant aller parfois jusqu'à la remise en question de l'existence de l'État d'Israël, désigné comme cause de tous les malheurs; position susceptible de rejoindre le militantisme en faveur d'un État binational comme solution à tous les problèmes. (5) Un militantisme pour «deux peuples, deux états", et un "sionisme propalestinien ».

Quels que soient le nom qu'on lui donne et les justifications dont on la pourvoit, cette hostilité à l'égard de l'Etat d'Israël — qui s'exprime le plus souvent par une critique radicale, arbitraire, voire pathologique, de tout ce que font ou ne font pas le gouvernement israélien, son armée et

59. Compte-rendu, sous le titre: "Quelques réflexions sur l'antisionisme». Intervention de Florence Taubmann, pasteur à l'Oratoire du Louvre présentée lors du colloque du 2 mai 2004 sur les "Juifs et Protestants aujourd'bui", disponible sur le site du Conseil Représentatif des Institutions juives de France (CRIF) à l'adresse suivante: $<$ www.crif.org/index02.php ?id=3295\&type $=$ dossiers\&menu=5>. Voir aussi F. Taubmann, Quelques réflexions sur l'antisionisme en France, <www.upjf.org/documents/showthread.php ?s=\&threadid=7141>. Les cinq points évoqués ici sont repris, presque mot à mot, de l'exposé du pasteur TAubmann. 
ses institutions politiques -, conjuguée à un parti pris propalestinien irrationnel est l'un des points cruciaux qui devraient faire l'objet des "sessions de débats", dont traite le présent article. Rarissimes, en effet, sont les intellectuels et théologiens chrétiens capables de «trier le bon grain de l'ivraie» dans les reproches incessants que l'on fait à l'État d'Israël, et assez courageux pour s'opposer au calomnies et au dénigrement systématiques dont il est l'objet, et qui sont responsables de ce qu'une partie croissante de l'opinion publique incline à remettre en cause, $a$ posteriori, la légitimité de l'existence d'Israël. À cet égard, le père Michel Remaud constitue l'une des exceptions, d'autant plus appréciées qu'elles sont rares; voici ce qu'il écrivait, l'an dernier, en réaction à un déni chrétien de la légitimité de la souveraineté israélienne:

"À l'époque contemporaine», peut-on lire dans [une revue catholique], «des juifs ont voulu recouvrer leur terre en faisant valoir leurs droits à la propriété de la Terre promise occupée depuis des siècles par d'autres peuples. C'est cette revendication qui est à l'origine de l'État d'Israël et des inextricables difficultés politiques de la Terre Sainte. Pour recouvrer leur terre, les Israéliens n'ont pas hésité à faire la guerre et à en chasser les occupants légitimes. " À quel épisode historique est-il fait ici allusion? Les premiers Juifs à venir s'installer sur cette terre à l'époque moderne et contemporaine, que ce soit après l'expulsion des Juifs d'Espagne en 1492, ou à partir de la première alya, en 1882, n'étaient pas des "Israéliens ». Ceux d'entre eux qui sont venus, pour des raisons religieuses, s'établir à Safed, Tibériade, Hébron ou ce qui allait devenir Mea Shearim, au cours des cinq derniers siècles, ne s'y sont pas implantés par la force des armes, et les immigrants, laïcs pour beaucoup d'entre eux, venus par vagues successives à partir de la fin du XIX e siècle n'ont pas cherché à reprendre la Palestine aux Turcs au moyen d'un débarquement armé! Les premiers «Israéliens» sont nés en 1948, avec l'État d'Israël. C'est une décision de l'ONU qui a créé cet État, et cette décision a été rendue possible par l'existence d'une importante population juive dans ce qui était devenu la Palestine britannique après avoir été la Palestine ottomane. Ajoutons qu'un certain nombre des "victimes malheureuses du Sionisme" - pour reprendre une formule de cet article - n'habitaient cette région que depuis quelques années, quelques décennies au plus, puisque des Arabes des régions voisines étaient venus s'établir en Cisjordanie à la suite de la déclaration Balfour, escomptant que la présence conjointe des Britanniques et des Juifs provoquerait un développement économique de la région [...]. Pour pouvoir conclure à l'illégitimité de l'État d'Israël, ce type de discours veut passer directement 
de la Bible à l'actualité politique en négligeant totalement les réalités historiques. Paradoxalement, il tombe du même coup dans le fondamentalisme qu'il semble reprocher aux Juifs. On ne fait rien avancer en remplaçant l'histoire par des mythes... ${ }^{60}$

Cette analyse me conduit à une mise en $\operatorname{garde}^{61}$ : Nous assistons aujourd'hui à l'acclimatation progressive, en Occident, d'une version proche-orientale de la phase 1 des années 30, durant laquelle « les témoins se taisaient ", alors qu'il était encore possible de dénoncer la diffamation et la violence antijuives. Pourtant, Dieu a prévenu: "Qui vous [les Juifs] touche m'atteint à la prunelle de l'œil!" $(\mathrm{Za} 2,12)$ Tous les chrétiens Dieu merci! - ne méritent pas la sévérité des analyses qui précèdent. Quelques-uns réagissent, çà et là, le plus souvent, hélas!, avec des moyens aussi minces que l'est leur audience. Il en faudrait bien davantage pour faire pièce à l'immense campagne de diffamation en cours. C'est d'un sursaut aux dimensions de la chrétienté tout entière qu'a besoin le peuple auquel l'Église a exprimé ses regrets. Et cela passe par une prise au sérieux de prophéties telles que celle-ci: «Sur tes remparts, Jérusalem, j'ai posté des veilleurs, de jour et de nuit, jamais ils ne se tairont. Vous qui remémorez [tout] au seigneur, ne restez pas inactifs. Ne lui accordez pas de repos qu'il n'ait établi Jérusalem et fait d'elle une louange au milieu du pays. » (Es 62,6-7) Car si les chrétiens se taisent, les Écritures crieront!

60. M Remaud, «Israël, État illégitime », Un Echo d'Israël 9 (15 juillet 2003), à lire sur le site du Portail francophone d'Israël: <www.afiq.net/echo/article.php3 ?id_ article=121 $>$. Ce thème s'acclimate de plus en plus dans l'opinion publique et trouve, à la faveur du conflit palestino-israélien, de nombreuses oreilles attentives. On peut en lire une expression quasi sacralisée dans des ouvrages - influencés par les thèses négationnistes du livre de R. Garaudy, Les Mythes fondateurs de la politique israélienne, publié à compte d'auteur en 1996, condamné et interdit de vente en France, mais largement diffusé sous le manteau et par des sites Internet tel celui de D. Vidal, Le péché originel d'Israël. L'expulsion des Palestiniens revisitée par les "nouveaux historiens" israéliens, Paris, L'Atelier, 1998. Depuis quelques années, cette critique dissolvante a fait des adeptes dans le monde chrétien; on en trouve, entre autres, une expression paranoïde dans un petit libelle délirant de F. Smyth-Florentin, Les mythes illégitimes. Essai sur la "terre promise ", Genève, Labor et Fides, 1994.

61. Je reprends ici des propos déjà exprimés dans M.R. Macina, "Si les Chrétiens se taisent, les Écritures crieront ", L’Arche, 519 (mai 2001) p. 34-38, accessible en ligne sur <www.rivtsion.net/documents/showthread.php ?s=\&threadid=2331>. 


\section{Conclusion}

Et toi, fils d'homme, prends un morceau de bois et écris dessus: Juda et les Israélites qui sont avec lui. Prends un morceau de bois et écris dessus: Joseph, bois d'Ephraïm, et toute la maison d'Israël qui est avec lui. Rapproche-les l'un de l'autre pour faire un seul morcean de bois; qu'ils ne fassent qu'un dans ta main [...]. Voici que je vais prendre les Israélites parmi les nations où ils sont allés. Je vais les rassembler de tous côtés et les ramener sur leur sol. J'en ferai une seule nation dans le pays, dans les montagnes d'Israël, et un seul roi sera leur roi à eux tous. (Ez 37,16s.)

Rappelez-vous qu'en ce temps-là vous étiez sans Christ, exclus de la cité d'Israël, étrangers aux alliances de la Promesse, n'ayant ni espérance ni Dieu en ce monde. Or voici qu'à présent, dans le Christ Jésus, vous qui jadis étiez loin, vous êtes devenus proches, grâce au sang du Christ. Car c'est lui qui est notre paix, lui qui des deux n'a fait qu'un. (Ep 2,12s.)

Qu'il me soit permis de terminer cet article par un vœu personnel. Ne conviendrait-il pas que des chercheurs juifs et chrétiens, ayant les compétences voulues pour ce faire, entreprennent des études théologiques comparées sur un thème trop négligé, alors qu'il est capital pour le rapprochement entre les deux communautés de foi ? Je veux parler de l'eschatologie ${ }^{62}$, ou plus exactement des conceptions juives et chrétiennes afférentes à la consommation du dessein de Dieu par l'avènement des Temps du Messie (yemot hamashiaḅ en hébreu).

J'en esquissais l'esprit, au terme d'une étude antérieure ${ }^{63}$, en citant un étrange midrash dans lequel deux Sages du Talmud reconnaissent que les chrétiens les ont supplantés, même si ce n'est que pour un temps, et où le «bœuf» représente Israël, tandis que le «cheval» et les «idolâtres» personnifient les chrétiens:

Que signifie: Toute face est devenue livide (Jr 30, 6)? - Rabbi Yohanan a dit: Il s'agit de la famille divine d'en haut [les anges] et de la famille divine d'en bas [Isrä̈l]. Et cela aura lieu [aux temps messianiques] lorsque le Saint, béni soit-Il, se dira: les uns [idolâtres = chrétiens] et les autres [Israël] sont l'œuvre de mes mains. Comment pourrais-je perdre les premiers pour ne laisser subsister que les derniers? Rav Pappa a dit: c'est

62. Voir la note 7 , ci-dessus.

63. M.R. Macina, "Caducité ou irrévocabilité de la première Alliance dans le Nouveau Testament? À propos de la "formule de Mayence" ", Istina 41 (1996) p. 395-400. 
comme le dicton populaire: quand le bœuf a couru et est tombé, on le remplace par le cheval à l'étable. (Talmud de Babylone Sanhedrin 98 b)

Rachi commente ainsi ce passage:

Ce que ne voulait pas faire [son maître, Dieu], avant la chute du bœuf [Israël], parce qu'il lui était extrêmement cher. Et lorsque, un jour ou l'autre, le bœuf est guéri de sa chute, il est difficile [au maître] d'évincer le cheval [idolâtres = chrétiens] au profit du bœuf, alors que Lui-même l'a mis [en place]. De même, le Saint — béni soit-Il! — voyant la chute d'Israël, a donné sa grandeur aux idolâtres [chrétiens]. Et lorsque Israël se convertit et est racheté, il Lui est difficile de perdre les idolâtres au profit d'Israël ${ }^{64}$.

Si, comme je l'espère, avec d'autres, «les deux» d'Ézéchiel et de Paul (cités ci-dessus en exergue de ma conclusion) prennent graduellement conscience de ce qu'ils sont UN dans le dessein divin, alors, au temps connu de Dieu seul, prendra tout son sens cette prophétie d'Isaïe:

Ils diront de nouveau à tes oreilles, les fils dont tu étais privée: "L'endroit est trop étroit pour moi, fais-moi une place pour que je m'installe.» Et tu diras dans ton cœur: "Qui m'a enfanté ceux-ci? J'étais privée d'enfants et stérile, exilée et rejetée, et ceux-ci, qui les a élevés? Pendant que moi j’étais laissée seule, ceux-ci, où étaient-ils ?» (Es 49,20-21)

"Ceux-ci », ce sont les païens qui ont cru à la messianité du rabbi juif de Galilée, nommé Jésus, eux qui jadis n'étaient pas un peuple et qui sont devenus peuple de Dieu (voir 1 P 2,10). Mais ensuite, oubliant que ce n'est pas eux qui portent la racine, mais la racine qui les porte, ils se sont enorgueillis (voir Rm 11,18s.), puis ont fait sécession, comme l'Israël du Nord, se séparant de Juda, par permission divine (voir 1 R 12,24)...

Dieu sait combien nous, Juifs, avons critiqué — souvent à juste titre - l'interprétation "typologique» de l'Écriture ${ }^{65}$, que les chrétiens ont si massivement utilisée jadis pour affirmer que notre foi, nos pratiques, voire nos Écritures, n'étaient que l'ombre de la «plénitude de sens chrétienne», et que l'Alliance divine avec l'Israël «selon la chair» était «vieillie et vétuste et près de disparaître»(He 8,13). Eh bien, c'est à la typologie que j'en appelle, à mon tour, pour proclamer ma foi en l'ac-

64. Macina, "Caducité ou irrévocabilité », p. 398-399.

65. Voir, à ce propos, SIDIC, 21/3 (1988), consacré à «La typologie et ses problèmes ». 
complissement inéluctable des promesses prophétiques d'une réunion de Juda et d'Israël (voir, entre autres, Os 2,2), où Juda est le type des Juifs, et Israël celui des chrétiens.

Piste féconde et prophétique, me semble-t-il, pour une recherche et une espérance communes ${ }^{66}$. Si ce travail peut inciter des croyants des deux confessions à la creuser, je m'estimerai amplement payé de mon labeur.

66. On trouvera de plus amples développements de cette typologie dans mon livre: M. Macina, Églises et peuple juif: le tournant du XX $X^{e}$ siècle, Paris, Albin Michel, à paraître en 2005 . 


\section{RÉSUMÉ}

Les sujets théologiques controversés qui divisent radicalement Juifs et chrétiens pourraient être abordés au cours de débats apparentés aux anciennes disputationes, mais menés dans un esprit de communion et d'estime mutuelle. À titre d'exemple, l'auteur explore quatre questions: (1) Comment concilier «le royaume vous sera enlevé» (Mt 21,43) avec l'irrévocabilité de l'alliance entre Dieu et le peuple juif, reconnue par l'Église? (2) Le royaume messianique s'établira-t-il sur la terre, ou dans les cieux? (3) Jésus peut-il être le Messie promis aux Juifs, alors que tant de prophéties ne sont pas accomplies et qu'Élie n'est pas venu (Ml 4,5) ? (4) L'État d'Israël: fait politique sans rapport avec l'histoire du salut ou "prémices de l'éclosion de la rédemption d'Israël»?

\section{ABSTRACT}

Controversial topics which are a source of sharp divisions between Jews and Christians could be addressed in the context of debates similar to the old disputationes, although conducted in a spirit of communion and mutual respect. To exemplify his point, the author explores four questions: 1) How can the statement "the kingdom of God will be taken away from you" (Mt. 21 :43) be compatible with the admission by the Church, of the irrevocable character of the covenant between God and the Jewish people? (2) Will the messianic kingdom be established on earth or in the heavens? (3) Can Jesus be considered as the Messiah promised to the Jews, since so many prophecies have not been fulfilled and the expected return of Elijah (Mal. 4:5) has not taken place yet? (4). Is the State of Israel a mere political reality, without any connection with the history of salvation, or the "first fruits of the opening of Israel's redemption"? 